\title{
Application of spectrophotometric methods for the determination of thiamine (VBI) in pharmaceutical formulations using 7-Chloro-4-Nitrobenzoxadiazole (NBD-Cl)
}

\begin{abstract}
Simple, swift and sensitive method for Spectrophotometric determination of thiamine (VB1) in pharmaceutical tablets has been described. The proposed method is based on the reaction of thiamine (VB1) and 7-Chloro-4-nitrobenzoxadiazole (NBD-Cl) at alkaline medium ( $\mathrm{pH}$ 10.5) to develop a deep brown adduct that bears maximum absorption at 434 $\mathrm{nm}$. Beer's law is obeyed in the concentration range $5-35 \mu \mathrm{g} / \mathrm{ml}$ of thiamine at the selected wavelength. Under optimized reaction conditions, the linear regression coefficients were $\mathrm{a}=0.033, \mathrm{~b}=-0.009$, and $\mathrm{r} 2=0.999$ calculated for the general equation of the calibration curve $(y=a x+b)$.

The limit of detection (LOD) and limit of quantification (LOQ) were found to be $0.667 \mu \mathrm{g} /$ $\mathrm{ml}$ and $2.020 \mu \mathrm{g} / \mathrm{ml}$ respectively. The method has been successfully applied to the determination of thiamine (VB1) in pharmaceutical formulations, and can be used as an alternative of the existing sophisticated method used in drug laboratories and factories.
\end{abstract}

Keywords: thiamine (VB1), spectrophotometric, pharmaceutical formulation, 7-Chloro4-nitrobenzoxadiazole (NBD-Cl)
Volume 2 Issue 3 - 2016

\author{
Sulafa Tageldin Abdel Rahman, ' Abdalla \\ Ahmed Elbashir,' Mohamed El Mukhtar,' \\ Mohamed Mustafa Ibrahim ${ }^{3}$ \\ 'Department of Chemistry, University of Sudan for Science and \\ Technology, Sudan \\ ${ }^{2}$ Department of Chemistry, University of Khartoum, Sudan \\ ${ }^{3}$ Department of Chemistry, University of Al-Baha, Saudi Arabia
}

\begin{abstract}
Correspondence: Abdalla Ahmed Elbashir, Department of Chemistry, Faculty of science, University of Khartoum, Sudan, Email aaelbashir@uofk.edu
\end{abstract}

Received: April 27, 2016 | Published: May 04, 2016
Abbreviations: LOD, limit of detection; LOQ, limit of quantification; VB1, Thiamine; FIA, flow injection analysis; NBD$\mathrm{Cl}$, 7-Chloro-4-Nitrobenzoxadiazole; $\mathrm{ICH}$, international conference on harmonization; HPLC, high-performance liquid chromatography; $\mathrm{RE}$, relative error

\section{Introduction}

Since Thiamine - the first discovered vitamin among B complex vitamins - is considered as an essential nutrient, ${ }^{1}$ and used for treatment of many disorders and diseases, ${ }^{2}$ and because it is included as a component of different multi-vitamins, a variety of analytical methods have been proposed for its determination in pharmaceutical formulations. Those methods include flow injection analysis (FIA), ${ }^{3-7}$ spectrophotometric ${ }^{8}$ chromatographic methods, ${ }^{9,10}$ fluorometry, ${ }^{11}$ high-performance liquid chromatography (HPLC), ${ }^{12,13}$ chemilumenescence, ${ }^{2}$ and electrochemical techniques. ${ }^{14,15}$

Most of those methods, though sensitive and reliable, are associated with several disadvantages. FIA methods require a pre-oxidation step of thiamine and extraction with chloroform. ${ }^{7}$ Other techniques such as HPLC and electrochemical techniques require highly sophisticated instrumentation besides tedious and time-consuming experimental steps. This sheds light to the need of alternative simple and sensitive methods for thiamine analysis.

Spectrophotometry is considered the most convenient analytical technique, because of its inherent simplicity, low cost, and wide availability in most quality control laboratories. ${ }^{16}$ 7-Chloro-4nitrobenzoxadiazole (NBD-Cl) is a well known fluorogenic and colorforming reagent that is widely used in the analysis of a variety of amino group containing drugs. ${ }^{17-20}$ Its use in pharmaceutical analysis was reviewed by Elbashir et al. ${ }^{17}$ and proved to be a convenient lowcost derivatizing reagent. ${ }^{21,22}$
Thus far, the reaction between Thiamine and NBD-Cl has not been reported yet. In a previous paper, we reported a sensitive and simple Spectrophotometric procedure for determination of Thiamine using NQS as color-developing reagent. ${ }^{8}$ In this context we report the determination of Thiamine using NBD-Cl as a reagent, and we establish the optimum reaction conditions necessary for reliable measurements in dosage forms.

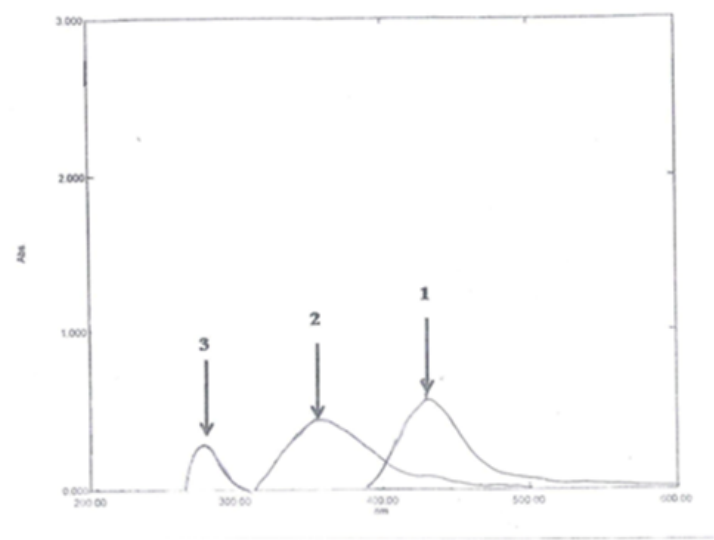

Figure I Absorption spectra of Thiamine (3), NBD-Cl (2) and the complex between them (I).

\section{Experimental}

\section{Apparatus}

Absorbance measurements were carried out using Shimadzu UV-Visible Spectrophotometer model 1800 with quartz cells of $1 \mathrm{~cm}$ optical path length, $\mathrm{pH}$ measurements were performed in $\mathrm{pH}$ meter model HI 255 (Hanna Instruments, Mumbai, India). Masses were taken using a digital Analytical Balance. 


\section{Material and reagent}

Thiamine hydrochloride was obtained from Sigma Aldrich Ltd, Khartoum, Sudan, and used as received; its purity was $99.15 \%$. A solution of 7-Chloro-4-nitrobenzoxadiazole (NBD-Cl) $0.2 \%(\mathrm{w} / \mathrm{v})$ was prepared by dissolving $0.2 \mathrm{~g}$ in distilled water, transferred into a $100 \mathrm{~mL}$ volumetric flask and diluted to the mark with distilled water then mixed well. The solution was freshly prepared and protected from light during use. A series of buffer solutions of $\mathrm{pH}$ range from $7-12$ were prepared according to the literature methods. ${ }^{23}$ An optimum buffer solution of $\mathrm{pH} 10.5$ was prepared by mixing $100 \mathrm{ml}$ of $0.025 \mathrm{M}$ aqueous solution of Borax with $36.5 \mathrm{ml}$ of $1 \mathrm{M}$ solution of sodium hydroxide and adjusted to $\mathrm{pH} 10.5$ with $1 \mathrm{M}$ Sodium hydroxide. All other chemicals were of analytical grade.

\section{Preparation of standard and sample solution \\ Stock standard solution of thiamine $(1000 \mu \mathrm{g} / \mathrm{mL})$}

An accurately $250 \mathrm{mg}$ of thiamine hydrochloride standard was dissolved in distilled water, transferred into $250 \mathrm{ml}$ volumetric flask, diluted to the mark with same solvent and mixed well. This stock solution was further diluted to $200 \mu \mathrm{g} / \mathrm{mL}$ to obtain working solutions in the range of $5-35 \mu \mathrm{g} / \mathrm{mL}$.

\section{Tablets sample solution}

Five capsules (Thiamine $100 \mathrm{mg} /$ capsule) were weighted and finely-grinded. A portion of the powder equivalent to $25 \mathrm{mg}$ of the drug was weighted and dissolved in distilled water, filtered and then transferred into 250 volumetric flask, completed to the mark with distilled water to give a solution of $100 \mu \mathrm{g} / \mathrm{mL}$. The solution was then subjected to chemical analysis according to the following procedure.

\section{Procedure of analysis}

Aliquots of $200 \mu \mathrm{g} / \mathrm{mL}$ of Thiamine was transferred into $10 \mathrm{ml}$ volumetric flask to give final concentrations of $5-35 \mu \mathrm{g} / \mathrm{mL}, 1.5 \mathrm{~mL}$ of 7-Chloro-4-nitrobenzoxadiazole (NBD-Cl) $0.2 \%(\mathrm{w} / \mathrm{v})$ was added and followed by $1.5 \mathrm{~mL} \mathrm{pH} 10.5$ buffer solution. The reaction was completed to volume with distilled water, and the resulting solution was measured at $434 \mathrm{~nm}$ against reagent blank treated similarly.

\section{Stoichiometry of the chemical reaction}

The method of continuous variation (Job's method): The Job's method of continuous variation was employed to determine the stoichiometric ratio of the reaction between thiamine and NBD$\mathrm{Cl}^{23}$ Equimolar $\left(7.5 \times 10^{-4} \mathrm{M}\right)$ aqueous solution of Thiamine hyrochloride and NBD-Cl were prepared. A series of $10 \mathrm{~mL}$ portions of Thiamine standard and NBD-Cl were made up comprising different complementary proportions $(1: 9, \ldots 9: 1$, inclusive $)$ in 10 $\mathrm{mL}$ volumetric flask containing $1.5 \mathrm{ml}$ of buffer solution $(\mathrm{pH}=10.5)$. The solution was further manipulated as described under the general recommended procedures. ${ }^{24}$

\section{Results and discussion}

\section{Absorption spectra}

The absorption spectrum of thiamine was recorded against water (Figure 1), it was found that thiamine exhibits a maximum absorption peak $\left(\lambda_{\text {max }}\right)$ at $235 \mathrm{~nm}$. Because of highly blue-shifted $\lambda_{\text {max }}$ of thiamine, its determination in the dosage form based on the direct measurement of its absorption for ultraviolet is susceptible to potential interferences from the common excipients. Therefore, derivatization of thiamine to attain visible-range absorbing species was undoubtedly necessary.
Thus, derivatization of thiamine with NBD-Cl was performed, and the absorption spectrum of the product was recorded against reagent blank (Figure 1). It was found that the product is brown colored exhibiting $\lambda_{\max }$ at $434 \mathrm{~nm}$, and the $\lambda_{\max }$ of NBD-Cl was $342 \mathrm{~nm}$. The $\lambda_{\max }$ of thiamine-NBD-Cl derivative was red-shifted, eliminating any potential interference. The wavelength $434 \mathrm{~nm}$ therefore was fixed as optimum.

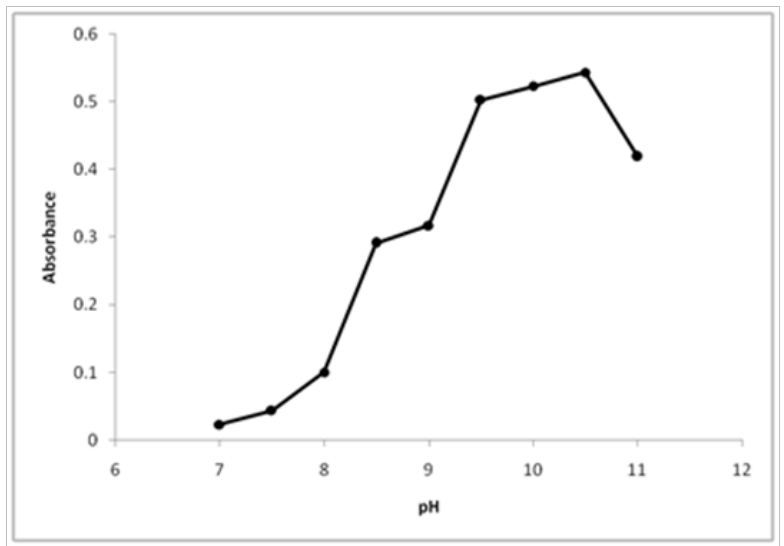

Figure 2 Effect of $\mathrm{pH}$ on the reaction of Thiamine with NBD-Cl. Thiamine $(20 \mu \mathrm{g} / \mathrm{ml})$ : I ml, NBD-Cl conc. $0.2 \%(\mathrm{w} / \mathrm{v})$, reaction time $20 \mathrm{~min}$.

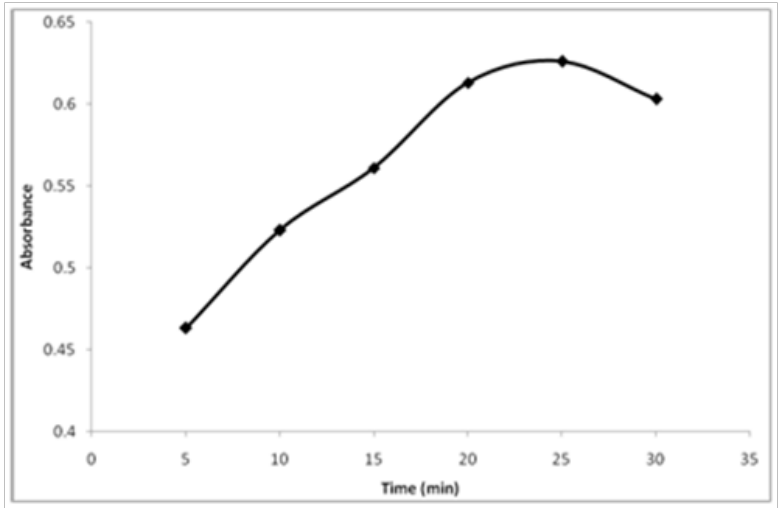

Figure 3 Effect of reaction time on the reaction of Thiamine with NBD-Cl. Thiamine $(20 \mu \mathrm{g} / \mathrm{ml})$ : I ml, Buffer (pH l0.5): $1.5 \mathrm{ml}$, NBD-Cl conc. 0.2\% (w/v).

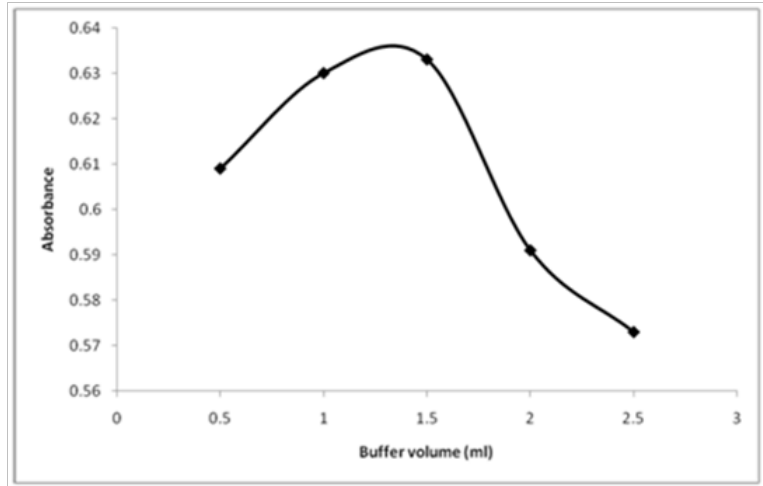

Figure 4 Effect of Buffer amount $(\mathrm{ml})$ on the reaction of Thiamine with NBD$\mathrm{Cl}$.

Thiamine $(20 \mu \mathrm{g} / \mathrm{ml}):$ I ml, Buffer $\mathrm{pH}: 10.5, \mathrm{NBD}-\mathrm{Cl}$ conc. $0.2 \%(\mathrm{w} / \mathrm{v})$, reaction time $25 \mathrm{~min}$.

\section{Optimization of the reaction conditions}

The optimum conditions for the developed method were established by varying the parameters one at a time while keeping 
the other parameters constant and following the effect exerted on the absorbance of the colored product. In order to establish experimental conditions, the effect of various parameters such as $\mathrm{pH}$, time, buffer volume and concentration of $\mathrm{NBD}-\mathrm{Cl}$ were investigated.

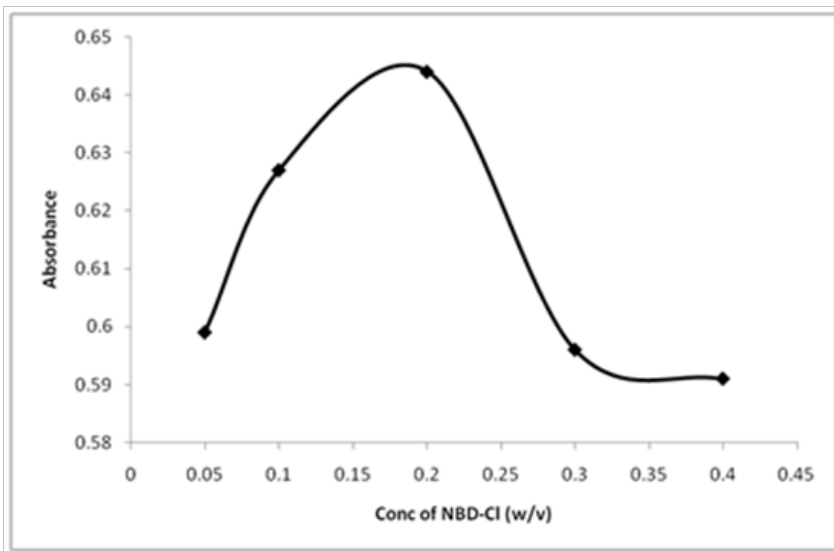

Figure 5 Effect of NBD-Cl concentration on its reaction with Thiamine.

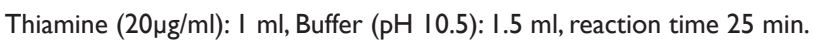

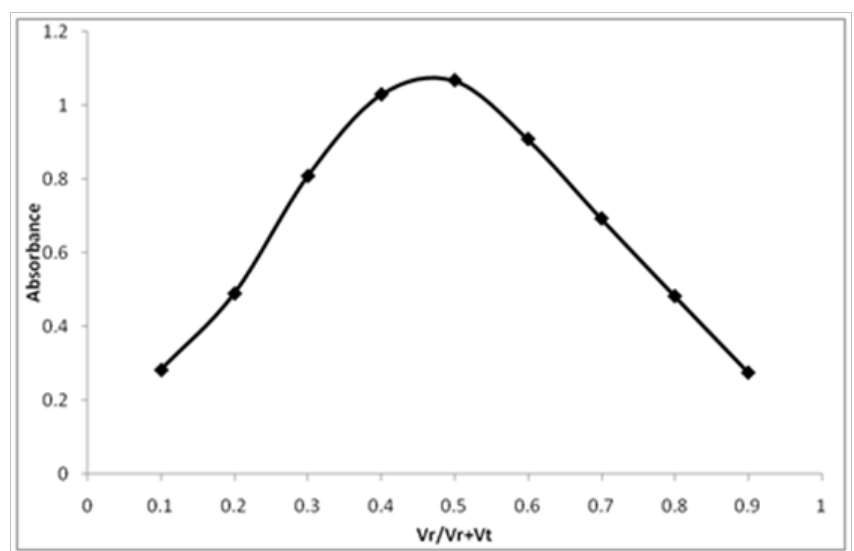

Figure 6 The Job's method plot for the stoichiometry of the reaction of Thiamine with NBD-ClVr:Volume of NBD-Cl $\left(7.5 \times 10^{-4} \mathrm{~mol} / \mathrm{L}\right), \mathrm{Vt}$ :Volume of Thiamine $\left(7.5 \times 10^{-4} \mathrm{~mol} / \mathrm{L}\right), \mathrm{Vr}+\mathrm{Vt}=10 \mathrm{ml}$.

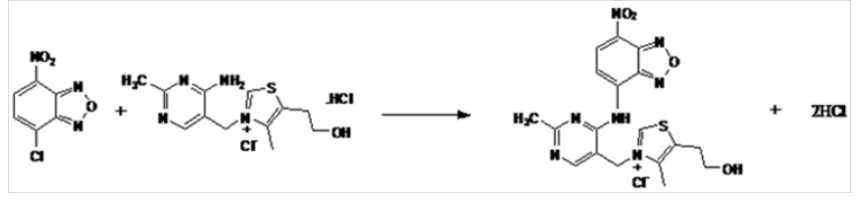

Figure 7 Reaction of Thiamine with NBD-Cl showing I:I stoichiometry.

\section{Effect of $\mathrm{pH}$}

The effect of $\mathrm{pH}$ on the reaction between thiamine and NBD-Cl was tested by varying the $\mathrm{pH}$ form 7.0 to 12.0. As shown in Figure 2 , the absorbance of the product is low at $\mathrm{pH} 7.0$, indicating that thiamine cannot react with (NBD-Cl) in neutral media. This was possibly due to the existence of the amino group of thiamine in the form of hydrochloride salt, which hampers nucleophilic substitution capability. As the $\mathrm{pH}$ increased from 7 to 12 , the readings increased dramatically, releasing the amino group of thiamine and facilitates the nucleophilic substitution. The maximum absorption was attained at $\mathrm{pH}$ value of 10.5. At $\mathrm{pH}$ values more than 10.5 , a decrease in the absorption occurred. This was attributed probably to the increase in the amount of hydroxide ion that increases the rate of the backward reaction of thiamine with NBD-Cl.
Table I Parameters for the performance of the proposed method

\begin{tabular}{ll}
\hline Parameter & Value \\
\hline Measurement wavelength $(\mathrm{nm})$ & 434 \\
Linear range $(\mu \mathrm{g} / \mathrm{mL})$ & May-35 \\
Regression equation & $\mathrm{y}=0.033 \mathrm{x}-0.009$ \\
Intercept & -0.00986 \\
Standard deviation of intercept & 0.00667 \\
Slope & 0.033 \\
Standard deviation of slope & 0.000298 \\
Correlation coefficient $\left(\mathrm{r}^{2}\right)$ & 0.9995 \\
Limit of detection, LOD $(\mu \mathrm{g} / \mathrm{mL})$ & 0.667 \\
Limit of quant., LOQ $(\mu \mathrm{g} / \mathrm{mL})$ & 2.0207 \\
\hline
\end{tabular}

Table 2 Recovery studies for the determination of thiamine by the proposed method

\begin{tabular}{lllll}
\hline $\begin{array}{l}\text { Sample } \\
\text { No }\end{array}$ & $\begin{array}{l}\text { Sample } \\
\text { Content } \\
(\mu \mathrm{g} / \mathrm{mL})\end{array}$ & $\begin{array}{l}\text { Thiamine } \\
\text { Standard } \\
\text { Amount } \\
(\mu \mathrm{g} / \mathrm{mL})\end{array}$ & $\begin{array}{l}\text { Amount } \\
\text { Found } \\
(\text { Total) } \\
(\boldsymbol{\mu g} / \mathrm{ml})\end{array}$ & Recovery \pm SD* \\
\hline 1 & 5 & 10 & 14.5 & $96.29 \pm 0.015$ \\
2 & 5 & 20 & 24.72 & $98.90 \pm 0.018$ \\
3 & 5 & 30 & 35.5 & $101.47 \pm 0.148$ \\
\hline
\end{tabular}

*Values are mean of three determinations.

Table 3 Evaluation of accuracy and precision

\begin{tabular}{lllll}
$\begin{array}{l}\text { Sample } \\
\text { No }\end{array}$ & $\begin{array}{l}\text { Concentration } \\
(\boldsymbol{\mu} / \mathbf{m L})\end{array}$ & $\begin{array}{l}\text { Concentration } \\
\text { Found }(\boldsymbol{\mu g} / \\
\mathbf{m L})\end{array}$ & $\begin{array}{l}\text { Recovery } \\
(\% \pm \mathbf{S D})\end{array}$ & $\begin{array}{l}\text { Relative } \\
\text { Error } \\
(\%)\end{array}$ \\
\hline 1 & 5 & 4.7 & $95.5 \pm 0.004$ & 0.224 \\
2 & 20 & 19.29 & $96.46 \pm 0.002$ & 0.15 \\
3 & 30 & 29.25 & $97.50 \pm 0.003$ & 0.24 \\
\hline
\end{tabular}

Table 4 Influence of small variation in the assay condition on the analytical performance of the proposed spectrophotometric method for determination of Thiamine using NBD-Cl reagent

\begin{tabular}{ll}
\hline Parameter & Recovery (\% \pm SD) \\
\hline Recommended condition & $97.50 \pm 0.003$ \\
NBD-Cl concentration $(0.22 \%)$ & $98.75 \pm 0.002$ \\
NBD-Cl concentration $(0.180 \%)$ & $96.76 \% \pm 0.003$ \\
Buffer PH(I0.7) & $96.90 \pm 0.002$ \\
Buffer PH(I0.3) & $95.79 \pm 0.22$ \\
Reaction Time $\min (23)$ & $96.09 \pm 0.009$ \\
Reaction Time $\min (27)$ & $98.01 \pm 0.003$ \\
\hline
\end{tabular}

Table 5 Analysis of Thiamine-containing dosage form by the proposed method

\begin{tabular}{lll}
\hline $\begin{array}{l}\text { Brand Name of } \\
\text { Label Claim (Mg) }\end{array}$ & $\begin{array}{l}\text { Amount } \\
\text { Found }(\mathbf{M g})\end{array}$ & (\% Found \pm SD) $^{\mathbf{a}}$ \\
\hline $\begin{array}{l}\text { Thiamine tablets } \\
(100 \mathrm{mg})\end{array}$ & 99.96 & $99.9 \pm 0.025$ \\
\hline
\end{tabular}

a: values are mean of five determinations.

\section{Effect of reaction time}

The absorbance of the reaction product was monitored at different times (Figure 3). Keeping other conditions intact, the absorbance of the reaction product was followed after standing for different time spans at $25^{\circ} \mathrm{C}$. The results show that thiamine reacts with NBD-Cl at $25^{\circ} \mathrm{C}$ and the absorbance begins to increase gradually and reach a maximum after $25 \mathrm{~min}$. For longer reaction times, a slight drop in the absorbance was observed. Accordingly $25 \mathrm{~min}$ was set as the convenient reaction time for determination. 


\section{Effect of amount of the buffer}

Keeping $\mathrm{pH}$ at 10.5 , the effect of amount of buffer solution on the absorbance of reaction product was also studied (Figure 4). The figure reveals that the absorbance of the reaction product enhances rapidly with the rise of amount of buffer solution, and becomes maximal when the amount of buffer solution reaches $1.5 \mathrm{~mL}$. Therefore, the amount of $1.5 \mathrm{~mL}$ buffer solution was selected to ensure the highest absorbance.

\section{Effect of NBD-Cl concentration}

The study of the effect of NBD-Cl concentrations showed that the reaction was dependent on the reagent concentration. The highest absorption intensity was attained at NBD-Cl concentration of $0.2 \%$ $(\mathrm{w} / \mathrm{v})$, and higher concentration of NBD-Cl leads to a decrease in the absorbance (Figure 5). From the above parameters-adjusting experiments, the optimized conditions used for the assay were: $\mathrm{pH}$ $10.5, \mathrm{NBD}-\mathrm{Cl}$ concentration $0.2 \%(\mathrm{w} / \mathrm{v})$, volume of the buffer $1.5 \mathrm{~mL}$, reaction time $25 \mathrm{~min}$ and temperature $25^{\circ} \mathrm{C}$.

\section{Validation of the method}

The method was validated for the following parameters: specificity, linearity, precision, accuracy, limit of detection (LOD), limit of quantitation (LOQ), and robustness according to the International Conference on Harmonization (ICH) guidelines. ${ }^{25}$

\section{Linearity, limit of detection (LOD) limit of quantification (LOQ)}

The linearity was evaluated by linear regression analysis determined by constructing seven concentrations of thiamine, in the range of 05 $35 \mu \mathrm{g} / \mathrm{mL}$, which was calculated by the least square regression method to calculate the calibration equation and the correlation coefficient. The calibration curves were constructed by plotting concentration versus absorbance, using linear regression analysis. The regression equation for the results was $\mathrm{A}=0.033 \mathrm{x}-0.009$ ( $\mathrm{r} 2=0.999)$, where $\mathrm{A}$ is the absorbance at $434 \mathrm{~nm}, \mathrm{x}$ is the concentration of thiamine in $\mu \mathrm{g} /$ $\mathrm{mL}$ in the range of $05-35 \mu \mathrm{g} / \mathrm{mL}$, and $\mathrm{r}$ is correlation coefficient (Table 1). It was found that the linear concentration range is comparable with our previous method using NQS. ${ }^{8}$ The limit of detection (LOD) and limit of quantification (LOQ) were determined according to the following formula $\mathrm{LOD}=3.3 \times \mathrm{SDa} / \mathrm{b}$, and $\mathrm{LOQ}=10 \times \mathrm{SDa} / \mathrm{b}, \mathrm{SDa}$ is the standard deviation of the intercept; $b$ is the slope under the ICH guidelines..$^{25}$ The LOD and LOQ were found to be 0.667 and $2.020 \mu \mathrm{g} /$ $\mathrm{mL}$, respectively (Table 1 ).

\section{Accuracy}

The accuracy of the proposed method was carried out by applying 3 different concentrations 10,20 , and $30 \mu \mathrm{g} / \mathrm{mL}$ of thiamine drug within linear range calculated as the percentage of the drug recovered from the samples (Table 2).

Relative error (RE) was within $0.24 \%$ with corresponding standard deviation within 0.004 for three different determinations (Table 3).

\section{Robustness}

Reaction mechanism: It has been reported that NBD-Cl reacts with amino group of primary or secondary amine derivatives. ${ }^{26-29}$ Similarly, amino group of thiamine can act as a nucleophile due to the lone pair of electrons on the nitrogen atom, trending to attack on the electron-deficient center in NBD-Cl (Table $4 \&$ Figure 6). At the same time, it has been proved that the composition of the product is $1: 1$ of thiamine and NBD-Cl (Figure 7). So it is concluded that amino group of thiamine react with NBD-Cl to form a brown adduct. The reaction equation is shown in Figure 7.

\section{Application of the proposed method to analysis of thiamine dosage form}

Thiamine tablets were subjected to the analysis by the proposed and the label claim agrees well with our new method as shown in Table 5. The proposed method has the advantage of being virtually free from interferences by excipients.

\section{Conclusion}

The present paper described the evaluation of NBD-Cl as analytical reagents in the development of simple, sensitive, and accurate spectrophotometric method for the determination of thiamine in pharmaceutical formulations. The proposed method is simple, reliable, specific, accurate, reproducible, and highly sensitive, for the determination of thiamine in commercially available dosage forms. The procedure presented here does not need necessitate any expensive apparatus; and can be used advantageously as a routine method for the determination of thiamine in quality control labs and industry. The method may be applied to the determination of other secondary amine derivatives as well.

\section{Acknowledgments}

None.

\section{Conflicts of interest}

Authors declare that there is no conflict of interest.

\section{References}

1. Barbara SS. A Simple and Sensitive Analytical Method for the Determination of Thiamine in Pharmaceutical Preparations. Journal of Analytical Chemistry. 2013;68(3):218-222.

2. Chengxiao Z, Guojun Z, Zhujun Z, et al. Highly sensitive electrochemical luminescence determination of thiamine. Analytica Chimica Acta. 1999;394(2-3):165-170.

3. Rocha FR, Fatibello FO, Reis BF. A multicommuted flow system for sequential spectrophotometric determination of hydrosoluble vitamins in pharmaceutical preparations. Talanta. 2003;59(1):191-200.

4. Pérez RT, Martnez LC, Sanz A, et al. Successive determination of thiamine and ascorbic acid in pharmaceuticals by flow injection analysis. J Pharm Biomed Anal. 2004;34(3):551-557.

5. Alonso A, Almendral MJ, Porras MJ, et al. Flow-injection solvent extraction without phase separation: Fluorimetric determination of thiamine by the thiochrome method. J Pharm Biomed Anal. 2006;42(2):171-177.

6. Oliveira CNC, Vicente PA, Aniceto C, et al. Flow injection turbidimetric determination of thiamine in pharmaceutical formulations using silicotungstic acid as precipitant reagent. Talanta. 1999;48(3):659-667.

7. Andrei F, Martinez J. FIA-Spectrophotometric determination of thiamine after uv-irradiation. Talanta. 1994;41(12):2147-2151.

8. Abdel RST, Elbashir AA, El-Mukhtar M, et al. Development and Validation of Spectrophotometric Method for Determination of Thiamine (VB1) in Pharmaceutical Formulations using 1, 2-Naphthoquine-4Sulphonate (NQS). Enliven: Bio analytical Techniques. 2015;2(1):1-6.

9. Marsza ML, Lebiedzinska A, Czarnowski W, et al. High-performance liquid chromatography method for the simultaneous determination of thiamine hydrochloride, pyridoxine hydrochloride and cyanocobalamin in pharmaceutical formulations using coulometric electrochemical and ultraviolet detection. J Chromatogr A. 2005;1094 (1-2):91-99. 
10. Tang X, Cronin DA, Brunton NP. A simplified approach to the determination of thiamine and riboflavin in meats using reverse phase HPLC. J Food Compos Anal. 2006;19(8):831-837.

11. Mohsen Z, Mohammad RG, Parviz N. Dispersive liquid-liquid microextraction followed by spectrofluorimetry as a simple and accurate technique for determination of thiamine (vitamin B1). Microchim Acta. 2010;168:317-324.

12. Hassan O, Chee MJ. Sensitivity of UV detection in simultaneous separation and detection of B-vitamins using HPLC. Malaysian Journal of Analytical Sciences. 2001;7(1):251-255.

13. Losa R, Sierra MI, Fernandez A, et al. Determination of thiamine and its phosphorylated forms in human plasma, erythrocytes and urine by HPLC and fluorescence detection: a preliminary study on cancer patients. J Pharm Biomed Anal. 2005;37(5):1025-1029.

14. Halvatzis Sk, Timotheous-Potamia M. Kinetic- potentiometric determination of ascorbic acid, biotin, pyridoxine hydrochloride and thiamine hydrochloride with n-bromosuccinimide. Analytica Chimica Acta. 1989;227(1989):405-419.

15. Hassan SSM, Elnemma E. Selective determination of thiamine (Vitamin B(1)) in pharmaceutical preparations by direct potentiometric argentometric titration with use of the silver-silver sulphide ion-selective electrode. Talanta. 1989;36(10):1011-1015

16. Sara AM, Abdalla AE, Hassan YAE. Spectrophotometric methods for the determination of gemifloxacin in pharmaceutical formulations. Acta Pharmaceutica Sinica B. 2011;1(4):248-253.

17. Elbashir AA, Krieger S, Schmitz OJ. Simultaneous determination of polyamines and acetylpolyamines in human urine by capillary electrophoresis with fluorescence detection. Electrophoresis. 2014;35(4):570-576.

18. Elbashir AA, Alfadil AAB. Development and Validation of Spectrophotometric Method for Determination of Penicillamine (PA) in Pharmaceutical Formulation Using 4-Choro-Nitrobenzo-2Oxa-1, 3-Diazol (NBD-CL). World Journal of Analytical Chemistry. 2013;1(2):18-22.

19. Basheir BEA. Elbashir AA. Spectrophotometric Method for Determination of L-Dopa in Pharmaceutical Formulation Using 7-Cholor- 4-Nitrobenzoxadiazole (NBD-CL) as A Chromogenic Reagent. European Journal of Pharmaceutical and Medical Research. 2015;2(1):304-316.
20. Mohammed TO, Elbashir AA. Spectrophotometric Method for Determination of Gabapentin in Pharmaceutical Formulation by Derivatization with 4-Chloro-7-Nitrobenzo-2-Oxa-1, 3-Diazole (NBD-Cl). International Journal of Drug Development and Research. $2015 ; 7: 1-4$

21. Elbashir AA, Suliman FO, Aboul EHY. The application of 7-chloro4-nitrobenzoxadiazole (NBD-CL) for the analysis of pharmaceuticalbearing amine group using spectrophotometry and spectrofluorimetry techniques. Applied Spectroscopy Reviews. 2011;46(3):222-241.

22. Elbashir AA, Suliman FO, Aboul EHY. The Application of 7-Chloro4-Nitrobenzoxadiazole and 4-Fluoro-7-Nitro-2,1,3 Benzoxadiazole for The Analysis of Amines and Amino Acids Using High-Performance Liquid Chromatography. Source Gazi University Journal of Science. 2011;24(4):679-697.

23. Robinson RA, Stokes RH. "Electrolyte Solutions" (2nd Edn), Butterworths: London; 1968.

24. Skoog DA, West DM, James HF, et al. Fundamentals of Analytical Chemistry, (8th edn), Cole Cengage Learning, USA; 2004. pp. 805.

25. ICH. Technical Requirements for the Registration of Pharmaceuticals for Human Use, Validation of analytical procedures: Text and methodology Q2 (R1). ICH Harmonised Tripartite Guideline; 2005. 1-17 p.

26. Klimisch HJ, Stadler L. Fluorimetric Bestimmung of nitrosamines after acid catalysed denitrification and obtaining of a derivative with 7 chloro 4 nitrobenzo 2 oxa 1,3 diazole. J Chrom. 1974;90(1):223-225.

27. Murray GM, Sepaniak MJ. HPLC laser fluorometric determination of amines in beer. Journal of Liquid Chromatography. 1983;6(5):931-938.

28. Tosunoglu S, Ersoy L. Determination of baclofen in human plasma and urine by high-performance liquid chromatography with fluorescence detection. Analyst. 1995;120(2):373-375.

29. Knabe J. Colorimetric and Fluorimetric Analysis of Organic Compounds and Drugs. Wiley online library. 1974;308(10):803-804. 